$\mathbb{T}$ periodica polytechnica

\author{
Transportation Engineering \\ $39 / 2(2011) 99+103$ \\ doi: 10.3311/pp.tr.2011-2.09 \\ web: http://www.pp.bme.hu/tr \\ (c) Periodica Polytechnica 2011
}

RESEARCH ARTICLE

\section{Congestion charging in Budapest - a comparison with existing systems}

\author{
Gábor Szendrő
}

Received 2010-09-06

\begin{abstract}
Transport is undoubtedly an extremely important sector in Europe. Accounting for 10\% of GDP, as well as 10 million workers, it is also a major source of pollution and noise emissions. The adverse effects of transport are amplified by congestion, resulting in traffic jams, aggravation for motorists and even more pollution. A number of different measures have been devised to address this problem, and to spare populated city centers from heavy traffic loads, while also promoting the "polluter pays principle". One of these measures is congestion charging, already implemented in several cities across Europe and worldwide, and may soon be introduced in Budapest. The purpose of this paper is to find a common ground for the schemes introduced in London and Stockholm, comparing them to the possible scheme in Budapest.
\end{abstract}

\section{Keywords}

congestion charging $\cdot$ area access fee $\cdot$ demand management

\section{Acknowledgement}

This work is connected to the scientific program of the "Development of quality-oriented and harmonized $R+D+I$ strategy and functional model at BME" project. This project is supported by the New Széchenyi Plan (Project ID: TÁMOP-4.2.1/B09/1/KMR-2010-0002).

\section{Gábor Szendrő}

Department of Environmental Economics, BME, H-1117 Budapest. Magyar Tudósok Krt. 2., Hungary

e-mail: szendro@eik.bme.hu

\section{Introduction}

Opinions are extremely divided in the judgment of this policy. The trade of transport claims that congestion charging serves traffic calming and environmental protection as a priority, financial benefit only comes second. So far, only a few cities have introduced some form of congestion charging, such as Singapore, Oslo, London and Stockholm. Gothenburg is also in the process of introduction, building heavily on the Stockholm example. Congestion charging influences vehicle usage by protecting a certain area from heavy traffic loads through a charge that must be paid upon entering the zone. Exemptions and reductions usually apply (ex. for medical or military vehicles, local residents).

Even though most motorists complied with regulations, the introduction of congestion charging led to an increase in specific crimes. In London, the number of vehicles carrying false number plates has increased significantly. According to estimations, the plates of 1 out of every 250 vehicles entering the zone were false (40 000 license plates were stolen in 2006 alone) [1]. The effect of congestion charging on businesses within the zone is controversial. Some businesses may report a loss in sales, while increased delivery costs are also an issue [2]. The former may drive an extension of opening hours to include weekends or holidays (when the charge does not apply). Since the charge affects different social strata to a different extent, the overall effect on business is likely neutral with large variations between shops. This may result in some businesses relocating outside the zone after the introduction of non-flat rate schemes.

Even though the primary goal of the charge is to reduce congestion (environmental aspects, concerns or targets were not listed among the reasons for introducing congestion charging in London, for example), environmental benefits are also realized through the net reduction in traffic volumes and the changes in modal split. Greenhouse gases, nitrous oxide and particulates can all be expected to decrease upon introducing charging, although whether sustained benefits can be achieved (as opposed to a one-off result at the time of introduction) is still a matter of debate, and studies are currently being undertaken to investigate this matter. Initial public resistance is likely to diminish after the first few months of introduction as positive effects are start- 
ing to materialize [3]. This can be observed in both the London and Stockholm cases, where public acceptance increased rapidly after introduction. As new austerity programs are being announced all over Europe, acceptance levels are likely considerably lower compared to pre-crisis levels.

\section{Short summary of the system in London}

The London scheme, introduced by TfL in 2003, is an ANPR (Automatic Number Plate Recognition) controlled, flat-rate system (daily charge: $£ 8 € 9$ covering $21 \mathrm{~km}^{2}$ in central London [4, 10]. Exemptions apply (residents of the zone are automatically eligible for $90 \%$ discount, public transport vehicles are automatically exempt - buses with at least 10 seats as well as taxis - motorbikes and bicycles also). The net proceeds of the scheme are to be used for "relevant transport purposes" by TfL, the Greater London Authority (GLA), or a London borough council.

There are a wide variety of options available for arranging payment. Daily, weekly, monthly or annual passes can be bought over the phone, the Internet, certain retail outlets, by post or text messages. There is no discount for prepayment.

\section{Short summary of the system in Stockholm}

Unlike the London scheme, the Stockholm congestion charging system is not a uniform entrance fee. Instead, it is differentiated by time and follows peak demand periods. Also, the congestion charge must be paid every time upon entering the zone, to a maximum of $60 \mathrm{SEK}(\sim € 6)$ [5]. The amount paid is deductible from the taxes of both businesses and individuals.

There are geographic and vehicle-based exemptions. Geographic exemptions apply when there is no viable alternative route (such as the island of Lidingö, which has its only connection to the mainland through the congestion charging zone). Emergency vehicles, buses (weight min. 14 t), diplomatic corps and military vehicles, motorcycles, vehicles registered in a foreign country, cars running on alternative fuels are automatically exempt (this last condition applies until July 3 2012). It should be noted that foreign vehicles are exempt because the Swedish system treats its measure as a tax, which by definition can not apply to foreigners. The same ANPR enforcement is used with the option to install a DSRC (Dedicated Short Range Communication) transponder. Contrary to the London scheme, the charges are summarized in a bill ("tax decision") which is sent to the vehicle's owner on a monthly basis and can also be viewed on the web page of the Swedish Road Administration by logging in [11].

\section{The prospective scheme in Budapest}

It must be emphasized that this congestion charging scheme is still a work in progress and there are few details available. It is reasonable to argue that charging should not be introduced until the public transport system is capable of handling the increased patronage due to the expected (favorable) changes in modal split. In practice, this means postponing introduction until at least Metro line 4 is completed and operational. As of writing this paper, Budapest Transport Plc. has annulled its contract with subway car manufacturer Alstom.

The scheme presented herein represents the most likely scenario, as published in a preliminary study by Városkutatás Ltd. [6]. It involves a system much like in London, an area access fee that must be paid daily, with no regard to the number of entries made. The fee is defined as 2.75 times the cost of a single ticket (800 HUF, $€ 2.75$ ), which helps in perpetually updating the system in order to prevent the charge from being irrelevant or too high.

Enforcement would use ANPR technology (around 300 planned gantries with cameras), with the option to install a DSRC unit. The charging zone can be seen on Fig. 1

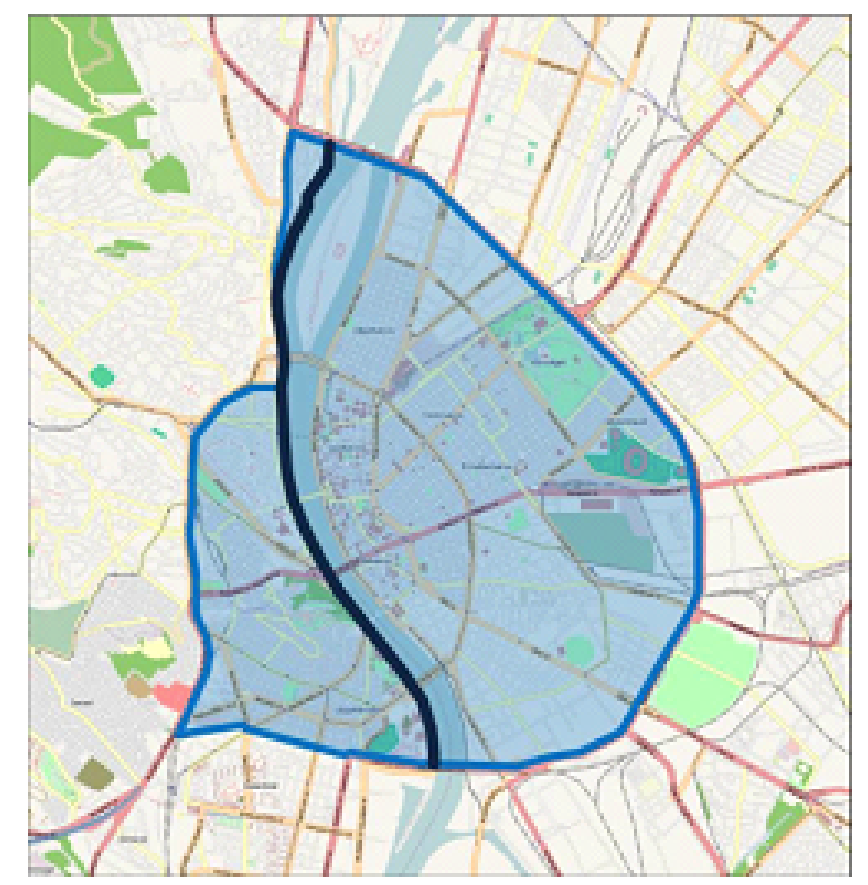

Source: 6]

Fig. 1. Planned charging zone in Budapest.

The charging zone covers downtown Budapest, bounded on the Pest side by the Hungária circuit. The charge-free transit route is marked in black (the Lower Quay on the Buda side). Having such a large area will require numerous gantries to monitor all possible entry points. The charge is flat rate, and does not follow peak demand periods [6]. Exceptions will likely be kept at the absolute minimum (public transport, taxis, law enforcement, ambulances, motorbikes, etc.), since the expected compliance rate is lower than in London or Stockholm, as demonstrated by the frauds and evasion techniques (such as unauthorized use of disability cards) used by motorists to avoid parking fees. Local residents will likely also have to pay, although the discount they will receive is as yet unclear (multipliers between 0.5 and 0.25 could work well, fraud and evasion screening will be problematic). The proposed scenario does not include multiple zones, even though the area covered is large enough to 
Tab. 1. Cost and revenues of the systems.

\begin{tabular}{lccc}
\hline Aspect & London & Stockholm & Budapest(planned) \\
\hline Charge area $\left(\mathrm{km}^{2}\right)$ & 21 & 30 & $\sim 50$ \\
Area percentage $(\%)$ & 1.32 & 7.9 & 9.5 \\
Charge amount $(€)$ & 9 & $1-2$ & 2.75 \\
Planning and research costs (million $€$ ) & 7.3 & 18 & - \\
Annual revenues (million $€$ ) & 236 & 91 & 147 \\
Supporting PT upon introduction & Yes & Yes & Deemed unnecessary \\
Source: own compilation, based on & & &
\end{tabular}

cover parts of Budapest (Zugló) that would merit a lower charge. The exemption of vehicles carrying foreign license plates is still an open question, enforcement will be difficult in light of the (successful) evasion techniques with such vehicles in the case of parking fees, speeding tickets and other fines, although the European Debt Collection Agency could provide an alternative, as was the case in London. For the purposes of this paper, foreignregistered vehicles are considered as exempt. The scheme can only be successful if the proceeds are earmarked for transport improvement purposes. As the Városkutatás study notes, one possible solution would be to set up a Transport Development Fund to manage the revenues generated [7].

\section{Comparison of the different systems}

Apart from its role in reducing congestion, charging is also a tool for internalizing other external costs resulting from transport (such as pollution). In this regard, flat-rate schemes are not as efficient. In an ideal situation, the charge that must be paid would be differentiated by the time of day, route taken and environmental class. It should be noted, however, that such an approach would require greater effort in monitoring the movement of vehicles. It would also result in greater complexity regarding the calculation of the charge. These effects would require substantially increased administration costs. Congestion tends to be less heterogeneous in peak hours, so the flat-rate charging, while not perfect, is not a bad approximation.

The funds required to set up the system and the revenues generated must also not be ignored. A comparative table of the different schemes can be found in Table ??.

It is clear that the Budapest zone is much larger compared to the other schemes. It should be noted that the increased patronage on public transport systems usually requires increased initial financial support (with a $10 \%$ foreseen change in modal split, this is both a quality and a quantity problem), an aspect the Budapest scheme seems to be lacking. Since the system in Budapest has not been introduced yet, its planning and research costs can not be determined. It is likely that more research and planning will be necessary if a well thought-out system is to be introduced [9].

The amount to be paid is also debatable and should be periodically reviewed to perpetually adapt the system. As prices and incomes rise, the amount to be paid, regardless of its initial value, will become less significant, and therefore the effects of the charge will diminish. If public transport demand or congestion just outside the charging zone increase dramatically, then the charge may be too high. If congestion is not substantially affected, then the charge is too low.

As a common ground for further comparison of the schemes, the Smeed Report seems a suitable starting point. Published in 1964, it suggested that drivers pay for the costs they imposed on each other. It also set out the design criteria for road pricing schemes which are still valid today [9]:

1 Charges should be closely related to the amount of use made of the roads

2 It should be possible to vary prices for different areas, times of day, week or year and classes of vehicle

3 Prices should be stable and readily ascertainable by road users before they embark upon a journey

4 Payment in advance should be possible although credit facilities may also be permissible

5 The incidence of the system upon individual road users should be accepted as fair

6 The method should be simple for road users to understand

7 Any equipment should possess a high degree of reliability

8 It should be reasonably free from the possibility of fraud and evasion, both deliberate and unintentional

9 It should be capable of being applied, if necessary, to the whole country and to a vehicle population expected to rise to over 30 million.

It should be noted that these criteria are meant to apply for those eligible for payment (exemptions should not be considered here). The original Smeed criteria have since been expanded to contain 12 aspects (see Table 2).

The following table compares the charging schemes against the extended Smeed criteria:

\section{Usage}

Charges should be a function of road usage. Neither scheme complies with this criterion, as the London and Budapest schemes are flat-rate, and the Stockholm system is only varied by time of day. 
Tab. 2. Comparison based on the extended Smeed Criteria

\begin{tabular}{lccc}
\hline Smeed Criteria & London & Stockholm & Budapest \\
\hline Usage & No & No & No \\
Price variation & No & Yes & No \\
Perfect Information & Yes & Yes & Yes \\
Payment & Yes & Yes & Yes \\
Fair & No & No & No \\
Simple & Yes & Yes & Yes \\
Reliable & Yes & Yes & Yes \\
Enforceable & Yes & Yes & Yes \\
Expandable & Yes & Yes & Yes \\
Foreigners & Yes & No & No \\
Privacy & Yes & Yes & Yes \\
Technology Integration & No & No & No \\
\hline (Source: Own compilation) & &
\end{tabular}

(Source: own compilation)

\section{Price variation}

Prices should be varied by area, vehicle type and time of day to better reflect social costs. As discussed above, the Stockholm scheme partly complies with this requirement by being timesensitive. Differentiation by environmental class and possibly by zones in Budapest is being discussed, but is not included in the proposed version to maintain simplicity (possibly creating a system that is less fair).

\section{Perfect information}

All road users should have the necessary information about pricing and how to pay before embarking on a journey. Both existing systems are, and the Budapest scheme is proposed to be in compliance with this requirement as information about the charging schemes is (will be made) readily available through a variety of channels.

\section{Payment}

Payment should be possible in advance and using several methods. Both existing systems fulfil this requirement. The Budapest payment system will likely include a mixture of electronic and on-site payment options.

\section{Fair}

The idea here is to impose higher charges on drivers with higher income. No scheme meets this criterion (differentiation by environmental class could actually have an opposite effect), although it is a valid point to argue that congestion charges cannot be unfair, since car owners usually have higher income. Also, since the proceeds from the schemes are used for transport investments, it can be stated that by paying the charge, derivers are financing improvements to the transport system that are of benefit to all.

\section{Simple}

All systems are quite simple and straightforward, easy to understand.

\section{Reliable}

As all systems share the same Automatic Number Plate Recognition system, they are all very reliable ( $\sim 90 \%$ accuracy). The initial problems (false number plates) in London have mostly been resolved, it is likely that the Budapest scheme will follow a similar pattern with a higher number of non-compliant drivers using foreign license plates.

\section{Enforceable}

All systems use a sophisticated system of photographs and number plates with special software to enforce payment, and they therefore meet this Smeed criterion. Evasion techniques (false or foreign license plates, etc.) can eventually be overcome (see above).

\section{Expandable}

All systems are based on a rugged framework that makes them expandable, thereby meeting this criterion, although the currently outlined plan for Budapest is unlikely to be expanded in the near future.

\section{Foreigners}

The London scheme allows anyone to easily pay the congestion charge if they are willing. Vehicles registered in the UK are easily identified, vehicles registered in other countries may be tracked down through a European Debt Collection Agency (although this process may be tedious and unsuccessful). Therefore, the London scheme complies with this criterion, as opposed to the Stockholm scheme, where foreign-registered vehicles are automatically exempt. The Budapest system will likely adopt a similar approach, as the enforcement of other regulations have already proved problematic for foreign-registered vehicles (Slovakia is especially popular).

\section{Privacy}

Both existing schemes respect the drivers' privacy, as images taken are automatically deleted from the system if the charge has been paid, and is only retained for enforcement purposes as evidence. It is expected that the Budapest scheme will follow suit.

\section{Technology integration}

The London scheme is quite basic (cameras and number plate recognition). Integration in this case would mean that the congestion charge could be paid with the same smart card, web page, etc. for different cities. The Stockholm system includes a DSRC transponder which, in theory, could serve integration, but it is an option only and is installed in a minority of vehicles. The same will likely be true for the Budapest system, although it can be argued that it is yet too early to consider integration. Consequently, none of the systems comply. 


\section{Final thoughts}

The London and Stockholm systems have been very effective and are considered to be successful both by their respective administrators and the general public. Initial low public acceptance has improved much in both cases after introduction, and solid results have been achieved. Therefore, both solutions should be considered as leading examples to other European cities that are contemplating the introduction of a congestion charging scheme.

As we have seen, most of the extended Smeed criteria are met by the London and Stockholm schemes (both fail 4), while Budapest fails 5, although these results should be taken with a grain of salt considering that the system is still under development. Perhaps the greatest challenge is the necessity of perpetual adaptation in order for the charge to remain fair and financially relevant. The Budapest plan is quite advanced in this respect, defining the charge as a function of the price of a single ticket.

The London and Stockholm systems are among the pioneers of congestion charging; hopefully Budapest will soon follow in their footsteps so that the effects of ever-increasing mobility demands, congestion, and pollution may be increasingly addressed in Europe and around the world.

\section{References}

1 Call for car number plate revamp, BBC, 2 June 2007. Retrieved 15 February 2008.

2 Transport for London: Congestion charging six months on, October 2003.

3 Eliasson J, Jonsson L, The unexpected "Yes!": explanatory factors behind the positive attitudes to congestion charging in Stockholm, 2009. ETC proceedings.

4 Institute for Fiscal Studies, Briefing Note No. 31: London's congestion charge.

5 Web page of the Swedish Transport Agency. (www.transportstyrelsen.se, acquired: October 23, 2010).

6 A fóvárosi személyforgalmi behajtási díj megvalósithatóságának elózetes vizsgálata, Városkutatás Ltd., 2009.

7 Schwarz-Herda F, Török Á, Siposs Á, Road toll policies in central and eastern European countries, Routes Roads 347 (2010), no. 3, 68-79.

8 Juhasz M, Liveable city - the possibility of introducing road toll in Budapest, Transport Sciences Review (February 2010).

9 Smeed R J, Road pricing: the economic and technical possibilities, 1964.

10 Transport for London: Congestion Charging Factsheet, July 2009.

11 Municipality of Stockholm: Facts and Results from the Stockholm Trial, December 2006. Final Version. 